\title{
Foucher's sign of the Baker's cyst
}

\author{
JUAN J CANOSO, ${ }^{1}$ MARTIN R GOLDSMITH, ${ }^{3}$ STEPHEN G GERZOF, ${ }^{3}$ \\ AND JEFFREY R WOHLGETHAN ${ }^{2}$
}

From the ${ }^{1}$ Department of Medicine, New England Medical Center; and the Departments of ${ }^{2}$ Medicine and ${ }^{3}$ Radiology, Boston Veterans Administration Medical Center, Boston MA

SUMMARY We investigated the mechanism of Foucher's sign, the change in pressure in the Baker's cyst with extension and flexion of the knee, by echography, arthrography, and computeç. tomography. With extension the gastrocnemius and the semimembranosus muscles approximate each other and the joint capsule compressing the cyst against the deep fascia. Opposite effects in $\dot{\omega}^{\omega}$ flexion allow the cyst to relax.

Key words: gastrocnemius-semimembranosus bursa.

Baker's cysts are pathological distensions of communicating gastrocnemius-semimembranosus bursae in patients with knee effusions. ${ }^{1-4}$ Only a small proportion of these cysts are diagnosed clinically. ${ }^{5}$ Symptomatic cysts may be detected as a mass, because of compression of vessels and nerves, or when their rupture results in a painful, swollen calf (pseudothrombophlebitis). ${ }^{6}$ Baker's cysts occur in the middle third of the popliteal fossa, emerging in the cleft between the gastrocnemius and the semimembranosus muscles. They become firm with full extension of the knee and soft when the joint is flexed. ${ }^{17}$ This finding, generally known as Foucher's sign, ${ }^{8}$ though it had been described by Adams in a case report, ${ }^{1}$ is useful for distinguishing Baker's cysts from lesions such as popliteal artery aneurysms, adventitial cysts, ganglia, and sarcomas, in which the palpatory findings are little affected by the position of the knee. To understand better the anatomical basis of this important clinical sign we used ultrasound, arthrography, and computed tomography to determine the effects of knee position and muscle contraction upon the cyst.

\section{Patients and methods}

Five consecutive patients with symptomatic Baker's cysts were entered into the study after informed consent (Table 1). The first three patients presented with large painful cysts. Patient 4 had pitting oedema of the leg and painful induration of the

Accepted for publication 12 August 1986.

Correspondence to Dr Juan J Canoso, Rheumatology, Box 406, New England Medical Center, 750 Washington Street, Boston, MA 02111, USA. medial head of the gastrocnemius; a large tende mass with a positive Foucher's sign had been present: on examination two days earlier. Patient 5 had hado intermittent knee swelling for three months. The evening before his admission he developed acute popliteal pain followed by diffuse calf swelling.

CLIN ICAL EXAMINATION

With the patient lying prone the tension of the cyst was determined by palpation with the knee first in $\vec{\delta}$ extension and then at 45 degrees flexion (Foucher's manoeuvre). With the limb in extension we then studied the effect of resisted knee flexion and $\overrightarrow{\mathrm{Q}}$. resisted plantar flexion of the foot. In two patient the effect of isometric contraction was studied a尺 various degrees of knee flexion.

ECHOGRAMS OF THE POPLITEAL REGION Echograms were performed with a Diasonics Wide Vue scanner (Sunnyvale, CA) with 7.5 and $10 \mathrm{MH}$ 웅 transducers. Patients were lying prone, in full knee extension. The popliteal and upper calf areas were scanned. Once the cyst was located attention wast paid to the cyst-muscle interphase during relaxation resisted flexion of the knee, and resisted plantap flexion of the foot.

A R T H R O G R A P H Y

After drainage of the joint air was injected slowl until the patient sensed pressure, typically after ${ }^{+}$ $50-60 \mathrm{ml}$. In two patients $5 \mathrm{ml}$ of Renografin- 60 was. also injected. Keeping the knee in extension, witl the patient lying on the affected side, an initial filn? was obtained. Then the popliteal area was inspecte under fluoroscopy while the knee was flexed 60-9ष् 
Table 1 Clinical characteristics of patients with symptomatic Baker's cysts

\begin{tabular}{|c|c|c|c|c|c|c|c|}
\hline $\begin{array}{l}\text { Patient } \\
\text { No }\end{array}$ & $\begin{array}{l}\text { Age } \\
\text { (years) }\end{array}$ & Sex & Clinical presentation & $\begin{array}{l}\text { Foucher's } \\
\text { sign }\end{array}$ & $\begin{array}{l}\text { Cyst's tension } \\
\text { with attempted } \\
\text { flexion against } \\
\text { resistance }\end{array}$ & Venogram & Diagnosis \\
\hline 1 & 62 & M & Painful popliteal mass & + & Increased & ND & Rheumatoid arthritis \\
\hline 2 & 53 & M & Painful popliteal mass & + & Increased & ND & $\begin{array}{l}\text { Osteoarthritis. } \\
\text { Crohn's disease }\end{array}$ \\
\hline 3 & 57 & $\mathbf{M}$ & Painful popliteal mass & + & Increased & ND & Psoriatic arthritis \\
\hline 4 & 33 & M & Painful, swollen calf & $-{ }^{*}$ & NA & Negative & $\begin{array}{l}\text { Osteoarthritis, joint } \\
\text { hyperlaxity }\end{array}$ \\
\hline 5 & 49 & $\mathrm{M}$ & Painful, swollen calf & - & NA & Negative & Gout? \\
\hline
\end{tabular}

${ }^{*}$ A cyst with positive Foucher's sign had been noted two days earlier.

$\mathrm{ND}=$ not done; $\mathrm{NA}=$ not applicable.

degrees. Films were obtained in flexion and after the knee had been returned to full extension.

COMPUTED TOMOGRAPHY

Immediately after arthrography computed tomography was performed with a Technicare 2060 fourth generation scanner (Technicare, Cleveland, $\mathrm{OH}$ ). Sections $(5 \mathrm{~mm})$ were obtained with a four second scanning time. Owing to technical limitations (diameter of the patient aperture) and difficulties in flexing the contralateral limb, several positions were used. In four patients both legs were studied simultaneously; three patients were prone and one was supine. Patient 4 , who had hyperlaxity of joints, was studied while lying on the affected side, with the contralateral limb flexed away from the aperture. In patients 1 and 2 a single section was obtained in each of three states of the knee $(a)$ extended, relaxed; $(b)$ extended, attempted flexion against resistance; and (c) flexed to 45 degrees, relaxed. In addition, sections through the upper calf were obtained in patient 1 during relaxation and resisted plantar flexion of the foot. In the remaining three patients sections were obtained every $1 \mathrm{~cm}$ through the length of the cyst.

\section{Results}

Foucher's sign was demonstrated in all three patients with palpable Baker's cysts (Table 1). With the leg in extension the tension of the cyst increased further with attempted flexion against resistance (Fig. 1). The effect of resisted flexion was lost at 30-45 degrees, corresponding to the relaxed phase of Foucher's sign. In two patients increased tension of the cyst was also produced by attempting plantar flexion of the foot against resistance.

Echograms were positive in the three patients with palpable Baker's cysts. No cysts were detected in the two patients with pseudothrombophlebitis,

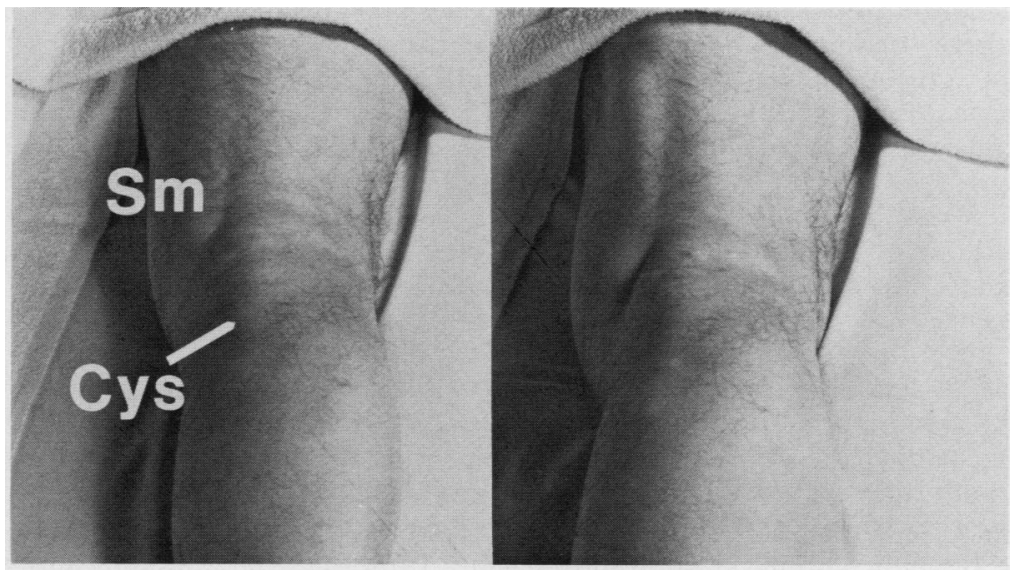

Fig. 1 Patient 1; right popliteal fossa. Left, muscles relaxed; right, resisted knee flexion. During resisted knee flexion the cyst (Cys) becomes harder, the semimembranosus $(\mathrm{Sm})$ more prominent, and the cleft between Cys and Sm deeper. 

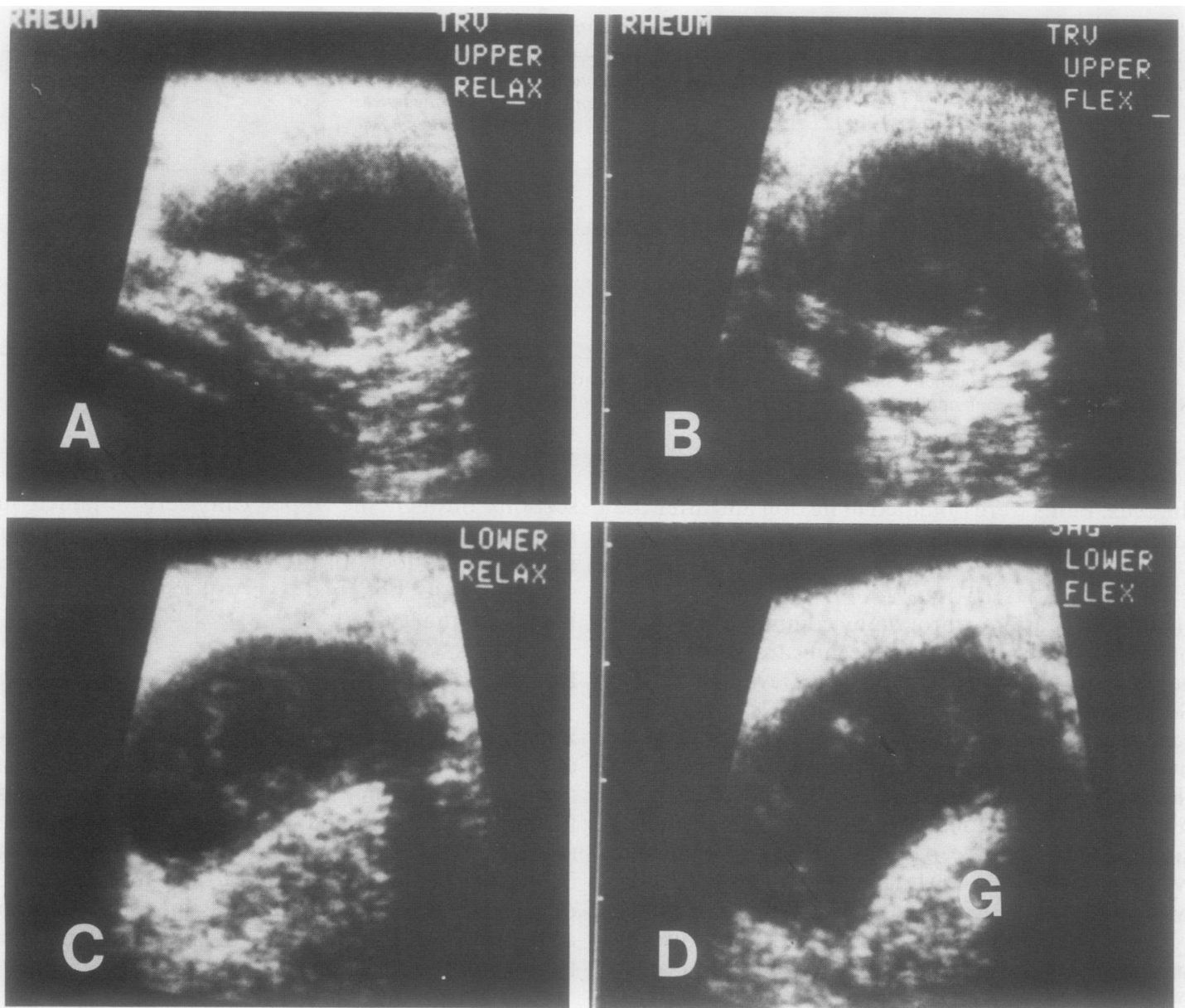

Fig. 2 Patient 3; echogram (transverse) of the right popliteal fossa. (A and C) Proximal and distal portions of the cyst, muscles relaxed; $(B$ and $D$ ) same, attempted knee flexion against resistance. Note the rounding of the cyst in $B$, and the impingement of the gastrocnemius $(G)$ upon the contents of the cyst in $D$.

but one showed marked oedema of the gastrocnemius. With resisted knee flexion there was rounding of the proximal portion of the cyst as the gastrocnemius bulged into the distal portion (Fig. 2). This effect was best demonstrated during repetitive contraction and relaxation.

In the arthrograms air entered the gastrocnemiussemimembranosus bursa during flexion of the joint in all patients. With knee extension, however, air persisted in the bursa only in patients with palpable Baker's cysts.

On computed tomography, with the knee in extension, the cyst appeared as a homogeneous mass in patient 1 and it was multilocular in patients 2 and 3 . In patients 4 and 5 the collapsed cyst appeared as a narrow slit between the gastrocnemius, the semimembranosus, and the joint capsule.
Flexion of the knee pulled the joint capsule awayo from the posterior aspect of the femoral condyles in all five patients. In the patients with palpable cysts $\frac{7}{2}$ (Fig. 3) the gap between the gastrocnemius and the semimembranosus widened. In the patients with $\tilde{\sigma}$ clinical rupture the gastrocnemius-semimem- $N$ branosus bursa filled with air, with actual ్ㅗ demonstration of the passage in one (Fig. 4).

\section{Discussion}

Previous computed tomographic studies of Baker's cysts were performed with the knee in extension. ${ }^{9-13} \frac{7}{0}$ They confirmed conclusions drawn from anatomical $\overrightarrow{\mathbb{D}}$ observations, in particular the relations of the cyst $\frac{\rho}{\mathbb{Q}}$ with the gastrocnemius and semimembranosus mus- $\varrho$ cles, and the joint capsule..$^{2-4}$ The findings during 

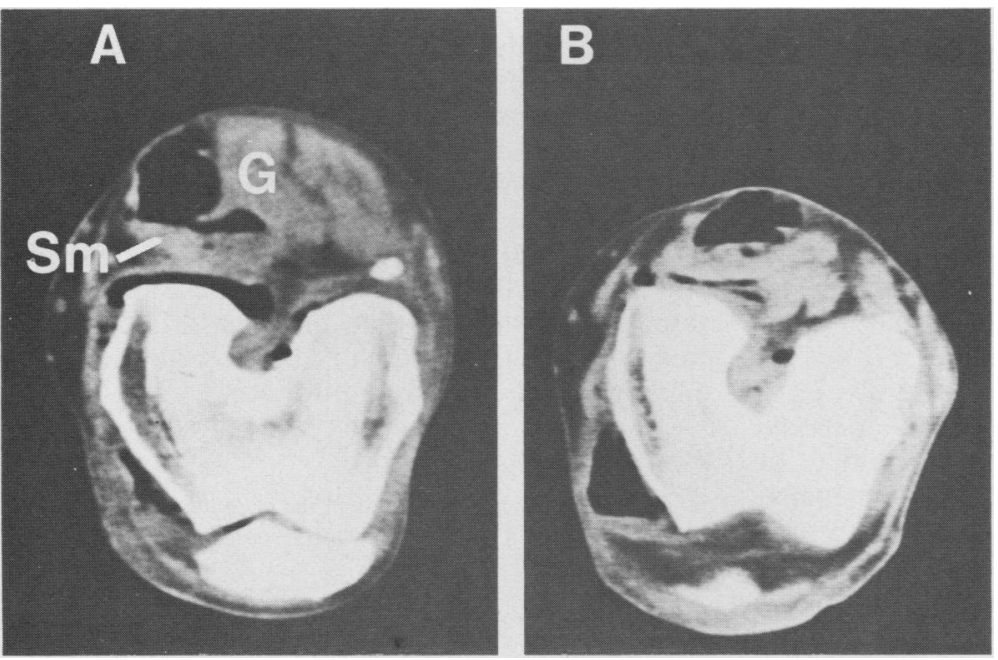

Fig. 3 Patient 2; ( $A$ and $B$ )

computed tomography of the left knee in flexion (A) and extension $(B)$. In extension the gastrocnemius $(G)$ and the semimembranosus $(\mathrm{Sm})$ come closer together and the cyst bulges beyond these muscles.
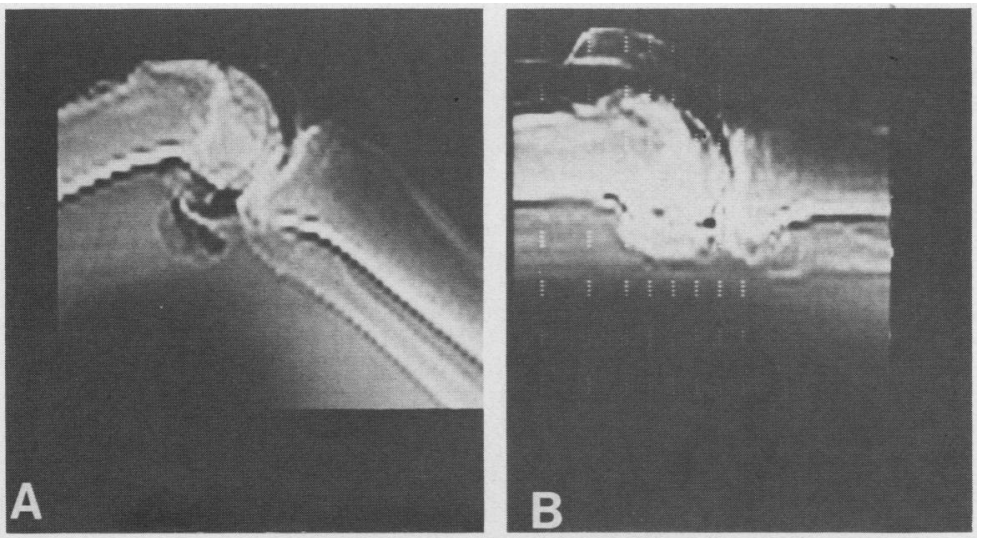

Fig. 4 Patient 4; ( $A$ and $B$ ) panoramic views of the left knee. (A) The bursa fills with air in knee flexion; $(B)$ collapse of the bursa in extension. ( $C$ and $D$ ) Computed tomography of the left knee in left decubitus. (C) A wide connection
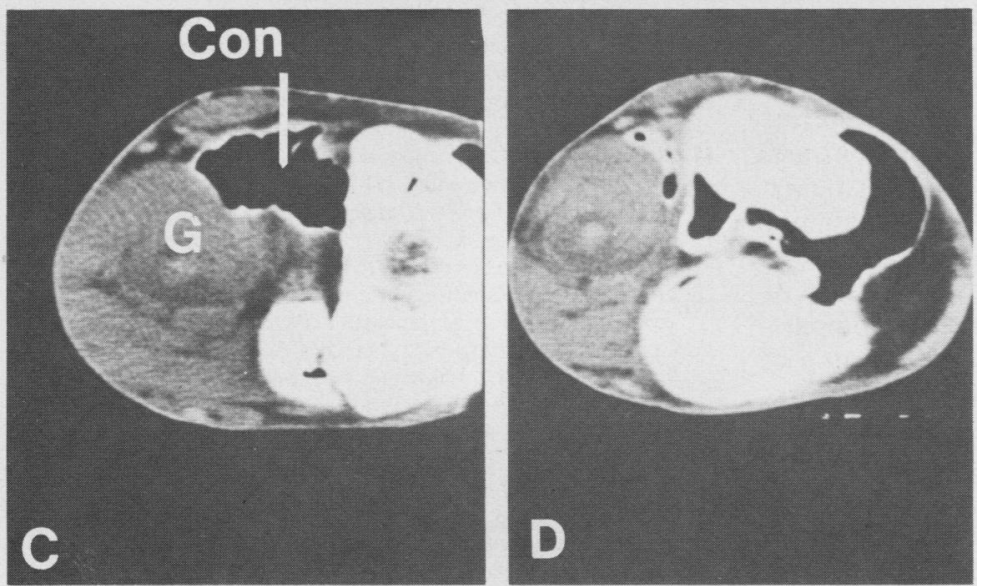
(Con) between bursa and joint is seen in flexion; $(D)$ the bursa collapses in extension due to compression by the gastrocnemius $(G)$. 
knee flexion and isometric muscle contraction were not addressed. Similarly, echography, which has been of great value in the diagnosis of unruptured cysts, ${ }^{5}$ has not been used to study the dynamic effects of muscle contraction upon the cyst.

We found that in patients with intact Baker's cysts knee extension compresses the cyst between the gastrocnemius and semimembranosus as they approximate each other and the joint capsule. The cyst's content is displaced posteriorly abutting the deep fascia. Isometric muscle contraction is associated with further compression of the cyst.

An interesting observation in our patients with pseudothrombophlebitis was the filling of what appeared to be a normal gastrocnemiussemimembranosus bursa during flexion; air was seen to enter and leave the bursa with repeated flexion and extension of the joint. The gap between joint and cyst, shown in one of our patients, is known to open with flexion, and to close with extension of the joint. ${ }^{14}$ Doppman showed by arthrography that in knee flexion, contrast medium is displaced from the suprapatellar synovial pouch to the posterior portion of the joint, with filling of connecting bursae or cysts; normal bursae emptied in extension, while Baker's cysts (proved by palpation) did not. ${ }^{15}$

Manometric studies in cadavers and patients have shown that knee extension is associated with high intracystic pressure; the highest pressure occurs with hyperextension, in which position the deep fascia and muscles binding the cyst are maximally stretched. With flexion of the knee the pressure falls; recordings in cyst and joint are virtually identical. ${ }^{714}$

Anatomically, Baker's cysts are located in the superficial posterior compartment of the leg. This compartment, which contains the gastrocnemius, soleus, and plantaris muscles, is limited anteriorly by the transverse intermuscular septum, and posteriorly by the deep fascia. ${ }^{16} \mathrm{~A}$ study of compartmental pressures in normals is pertinent to our findings. ${ }^{17}$ In the resting extended position dorsiflexion of the foot raises the pressure in the posterior superficial compartment of the leg. In contrast, pressures are slightly lower when the knee is flexed 90 degrees with the foot in full passive plantar flexion. Based on these observations and our findings, we suggest that owing to mass effect or leakage Baker's cysts potentiate normal compartmental pressure changes induced by the position of ankle and knee. Increased compartmental pressure, rather than direct compression, would explain some of the peripheral nerve dysfunctions associated with Baker's cysts. ${ }^{18}$ In at least one instance a clinically diagnosed Baker's cyst was complicated by the deep compartmental syndrome. ${ }^{19}$
We concur with Doppman ${ }^{15}$ that a structure seen to fill with knee flexion and collapse with ex- $\vec{F}$ tension represents a normal gastrocnemiussemimembranosus bursa. A distended bursa should be considered a 'cyst' only when it bulges beyond the gastrocnemius and semimembranosus in knee extension. It is the action of these muscles which defines the Baker's cyst, causes it to harden with os extension, and leads to its rupture. These anatomical observations suggest that the best treatment to prevent imminent rupture of a Baker's cyst would be splinting of the knee in semiflexion.

\section{References}

1 Adams R. Abnormal anatomy of the knee joint. In: Todd RB, ed. Cyclopaedia of anatomy and physiology. Vol 3. London: N Longman, 1839-1847: 57-60.

2 Wilson P D, Eyre-Brook A L, Francis J D. A clinical and 0 anatomical study of the semimembranosus bursa in relation to popliteal cyst. J Bone Joint Surg 1938; 20: 963-84.

3 Lindgren P G. Willén R. Gastrocnemio-semimembranosus bursa and its relation to the knee joint. I. Anatomy and histology. Acta Radiol /Diagn/ (Stockh) 1977; 18: 497-512.

4 Rauschning W. Popliteal cysts and their relation to the gastrocnemio-semimembranosus bursa. Uppsala: Upplands Grafiska, 1979. (Doctoral dissertation at Uppsala University.) .

5 Fam A G, Wilson S R, Holmberg S. Ultrasound evaluation of popliteal cysts in osteoarthritis of the knee. J Rheumatol 1982: 9: $428-34$.

6 Katz R S, Zizic T M, Arnold W P, Stevens M B. The pseudothrombophlebitic syndrome. Medicine (Baltimore) 1977; 56: $151-64$

7 Jayson M I V. Dixon A St J. Valvular mechanisms in juxta-articular cysts. Ann Rheum Dis 1970; 29: 415-20.

8 Foucher E. Mémoire sur les kystes de la région poplitée. Arch Gen Med 1856; 8: 425-43.

9 Cooper R A. Computerized tomography (body scan) of Baker's cyst. J Rheumatol 1978; 5: 184-9.

10 Lee K R, Tines S C. Price H I, De Smet A A, Neff J R. The computed tomographic findings of popliteal cysts. Skeletal Radiol 1983; 10: 26-9.

11 Passariello R. Trecco F, De Paulis F, Bonanni G, Masciocchi C, Zobel B B. Computed tomography of the knee joint: technique of study and normal anatomy. J Comput Assist Tomogr 1983; 7: 1035-42.

12 Passariello R. Trecco F, De Paulis F, De Amicis R, Bonanni G, Masciocchi C. Computed tomography of the knee joint: clinical aspects. J Comput Assist Tomogr 1983; 7: 1043-9.

13 Schwimmer M. Edelstein G, Heiken J P, Gilula L A. Synovial 을 cysts of the knee: CT evaluation. Radiology 1985; 154: 175-7. N

14 Lindgren P G. Gastrocnemio-semimembranosus bursa and its $\sigma$ relation to the knee joint. III. Pressure measurements in joint $\mathrm{N}$ and bursa. Acta Radiol /Diagn/ (Stockh) 1978; 19: 377-88.

15 Doppman J L. Baker's cyst and the normal gastrocnemiosemimembranosus bursa. AJR 1965; 94: 646-52.

16 Lockhart R D, Hamilton G F. Fyfe F W. Anatomy of the human body. Philadelphia: Lippincott, 1959; 242-5.

17 Gershuni D H, Yaru N C, Hargens A R, Lieber R L, O’Hara R C. Akeson W H. Ankle and knee position as a factor modify- $\stackrel{\mathscr{S}}{+}$ ing intracompartmental pressure in the human leg. J Bone Joint $T$ Surg [Am] 1984; 66: 1415-20.

18 Nakano K K. Entrapment neuropathy from Baker's cyst. JAMA 1978; 239: 135.

19 Scott W N, Jacobs B, Lockshin M D. Posterior compartment syndrome resulting from a dissecting popliteal cyst. Clin Orthop 1977: 122: 189-92. 